\title{
A new technique for investigating the induced and profile drag coefficients of a smooth wing and a tubercled wing
}

\author{
Michael Bolzon ${ }^{1}$, Richard Kelso ${ }^{1}$ and Maziar Arjomandi ${ }^{1}$ \\ ${ }^{1}$ The School of Mechanical Engineering, The University of Adelaide, South Australia, Australia, 5005.
}

\begin{abstract}
The induced and profile drag coefficients of a wing are typically determined through a complex experimental technique, such as wake surveying. Such a technique requires measurement of all three orthogonal components of the downstream velocity to find the components of drag, which results in the necessary usage of a sophisticated and costly measurement device, such as multi-hole pressure probe. However, in this paper data is presented which demonstrate that the relative changes in the induced and profile drag coefficients can largely be determined through the sole measurement of the downstream, streamwise velocity. To demonstrate this, the induced and profile drags of two NACA 0021 wings, one with a smooth leading edge and the other wing a tubercled leading edge for comparison, are determined through the measurement of the three orthogonal velocities. The downstream, streamwise velocity distribution of each wing is then constructed and relationships can be determined. The wings were surveyed at $3^{\circ}, 9^{\circ}$, and $12^{\circ}$. It has been found that the relative magnitude of the profile drag coefficient can be found for all considered angles of attack, while the relative magnitude of the induced drag coefficient can be found at $9^{\circ}$ and $12^{\circ}$. These findings produce an innovative, simpler, and more cost effective experimental technique in determining the components of drag of a wing, and reduces the burdensome requirement of a sophisticated measurement device for such an experiment. Further investigation is required to determine the induced drag at $3^{\circ}$.
\end{abstract}

\section{Introduction}

The drag of a wing is an important parameter as it largely determines the wing's efficiency. While it is a relatively simple task to determine a wing's drag, such as through the use of load measurements, designing a wing to produce less drag is far more complex. The drag can be divided into two components; the induced and profile drags. In order to reduce the drag of a wing one of these two components can be targeted, however, a positive effect on one component can often lead to a negative one for the other, for example tripping a boundary layer may result in a reduced profile drag, but this also results in an increased induced drag. For some flow control devices the total drag coefficient may increase. Therefore, in order to reduce the overall drag of a wing both the induced and profile drags must be considered during the design phase, and consequently these two components of drag must be measured. The profile drag is greatly affected by flow separation, as a greater flow separation results in a greater pressure drag, which is a constituent of profile drag. Therefore, determining to what extent the flow over a wing has separated will provide valuable insight into the relative magnitude of the profile drag. Furthermore, for swept wings the flow tends to separate first at the wingtip, which reduces the circulation in this region, and in turn reduces the induced drag. Therefore, determining the location and extent of flow separation will also indicate the relative induced drag.

A typical method used to investigate the induced and profile drags of a wing is to perform a wake survey, whereby the wing is placed in a wind tunnel and a plane downstream of the wing is designated as the "wake plane", as detailed in figure 1. This wake plane is then divided into a grid of nodes and the three orthogonal velocities are measured at each node. From these three orthogonal velocities the induced and profile drags can be computed from Eqs. 1 and 2 [1]. To measure the necessary three orthogonal velocities requires a sophisticated tool, such as a multi-hole pressure probe, which is typically expensive to purchase or labour intensive to manufacture and calibrate. The ability to measure induced and profile drags then becomes limited to a select few, and hence impacts the progress of wing design. Naturally, a question arises as to whether the induced and profile drags can be investigated without knowing three orthogonal velocities. By reducing the number of parameters that must be measured a simpler methodology that can be utilised by a greater number of researchers, may result, thereby accelerate the wing design process.

\footnotetext{
${ }^{\mathrm{a}}$ Corresponding author: michael.bolzon@adelaide.edu.au
} 
The drag created by a wing will manifest itself as a reduction in the downstream, streamwise velocity component, as such by studying the streamwise velocity distribution in the wake plane the drag distribution over a wing can be ascertained. Over a conventional wing the vast majority of the induced drag originates at the wingtip, whereas the profile drag generally occurs over the entire span. Therefore, by considering the downstream, streamwise velocity in certain regions it may be possible to qualitatively deduce the induced and profile drags of a given wing. While the streamwise velocity profile will only serve as a qualitative indication of the induced and profile drags, this method is well suited to preliminary investigations into wings with new flow control devices or planform shapes, as the effects on the induced and profile drags will be evident when comparing two wings. If the induced and profile drags can be investigated from the downstream, streamwise velocity profile then a tool as common and inexpensive as a Pitot-static probe will suffice. The aim of this investigation is to determine whether any patterns exist between the downstream, streamwise velocity distribution and the induced or profile drag coefficients, or the flow separation over a wing. To do so, a comparison of two wings, one with a smooth leading edge and the other with a tubercled leading edge, is performed as it is known that the flow physics over a tubercled wing is different to that over the smooth wing [2].

\section{Method}

In order to determine whether the induced and profile drag coefficients can be investigated through the downstream, streamwise velocity distribution, a wake survey has been conducted on two wings. The wings are shown in figure 2 and are identical except that one has a smooth leading edge while the other has a new flow control device known as tubercles. The wings have a NACA 0021 profile, a quarter chord sweep angle of $35^{\circ}$, a taper ratio of 0.4 , a root chord of $175 \mathrm{~mm}$, and the tubercles have a constant amplitude of $10.5 \mathrm{~mm}$ and a

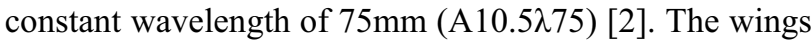
were $\mathrm{CNC}$ machined from aluminium and the tubercles were implemented to preserve a constant thickness-tochord ratio along the entire wingspan. This resulted in chordwise "bumps" and "valleys" forming over the peaks and troughs, respectively, along the chord. These features washed out towards the trailing edge. The wake survey was conducted with a Turbulent Flow Instruments brand multi-hole pressure probe known as a Cobra probe, from which three orthogonal velocities can be found and the induced and profile drags can be computed from Eqs. 1 and 2. The downstream, streamwise velocity distribution can also be found from the same measurements. The wake plane was located $390 \mathrm{~mm}$ downstream of the wing's root trailing edge, as shown in figure 1 . The wake plane size differed for each angle of attack, as expected, because the wake size grew with increasing angle of attack. Therefore, to reduce experimental time the wake plane size was smaller for lower angles of attack, however, it was kept consistent between the smooth and tubercled wings for any given angle of attack. The wake plane was divided into nodes spaced $6 \mathrm{~mm} \times 6 \mathrm{~mm}$ apart. The wings were placed on a JR3 load cell, which was placed on a Vertex brand rotary table, in turn. The load cell was used to determine the $0^{\circ}$ angle of attack of the wing, while the rotary table was used to change the wing's angle of attack. The experimental setup can be seen in figure 1 . The wake survey was conducted in The University of Adelaide's "KC" open-return wind tunnel with a freestream velocity of the wind tunnel was $27.5 \mathrm{~m} / \mathrm{s}$, which resulted in a Mean Aerodynamic Chord, MAC, Reynolds number of 225,000. The turbulence intensity of the wind tunnel is $0.6 \% \sim 0.8 \%$. The wings were placed at $3^{\circ}, 9^{\circ}$, and $12^{\circ}$. At $3^{\circ}$ both wings produce induced drag and were performing at a regular low angle



Figure 1. Wake survey setup depicting smooth wing. 
of attack. At $9^{\circ}$ the flow over both wings was still mostly attached, whereas at $12^{\circ}$ it was found by Bolzon et al. [3] that the flow over the tubercled wing began to separate near the wingtip greatly, which resulted in an increase in the profile drag coefficient and reduction in the induced drag coefficient [4]. However, this flow separation was localised to the final trough [5]. Therefore, comparing $9^{\circ}$ to $12^{\circ}$ is of high interest as it marked an appreciable change in the flow patterns over the tubercled wing, therefore, comparing the induced and profile drag coefficient distributions of the smooth and tubercled wings at these angles of attack may reveal potential relationships between the induced and profile drag coefficient distributions, and the extent of flow separation, and the downstream, streamwise velocity distribution.

$$
\begin{gathered}
D_{i}=\iint_{\mathrm{S}} 1 / 2 \rho_{\infty}\left(v^{2}+w^{2}-u^{2}\right) \cdot d y \cdot d z, \\
D_{p}=\iint_{\mathrm{S}} P_{t \infty}-P_{t}+1 / 2 \rho_{\infty}\left(u^{*}-u\right)\left(u^{*}-u-u_{\infty}\right) \cdot d y \cdot d z,
\end{gathered}
$$

where

$$
u^{*}=\left(u^{2}+(2 / \rho)\left(P_{t \infty}-P_{t}\right)\right)^{1 / 2}
$$

and

$$
u^{\prime}=u^{*}-u_{\infty}
$$

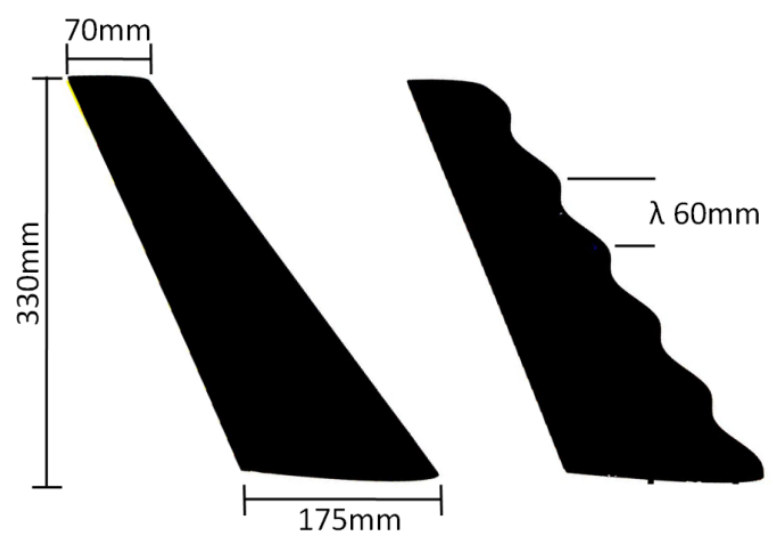

Figure 2. The smooth and tubercled wings manufactured, dimensioned.

\section{Results}

The induced and profile drag coefficients, and the downstream, streamwise velocity distributions of the smooth and tubercled wings at $3^{\circ}, 9^{\circ}$, and $12^{\circ}$ can be seen in figures 3 to 20 . The velocity gradients of the downstream, streamwise velocity distributions have been included on the figures.

\subsection{The Effects of the Induced Drag Coefficient on the Downstream, Streamwise Velocity Distribution}

At an angle of attack of $3^{\circ}$, as shown in figures 3 and 4 , the vast majority of the induced drag coefficient of either wing occurred near the wingtip, as expected. However, while this finding is promising in that the induced drag coefficient was concentrated in a relatively small area, and as such any changes in the induced drag coefficient should translate directly to the downstream, streamwise velocity distribution, the profile drag coefficient in the wingtip region was substantially higher, as shown in figure 5 and 6 . The reason why the profile coefficient drag was high in the wingtip region was because there was significant flow separation over the wingtip of each wing, which caused an increase in pressure drag [5]. Therefore, using the superficial idea that any change in the downstream, streamwise velocity in the wingtip region is indicative only of the induced drag coefficient is false, and a better criterion must be made in order to decouple the induced drag coefficient effects from the profile drag coefficient effects.

Up to $9^{\circ}$ the flow over the wings was relatively consistent, with the flow staying largely attached. However, increasing the tubercled wing's angle of attack from $9^{\circ}$ to $12^{\circ}$ resulted in the wingtip to stall, whereas the flow over the smooth wing's wingtip continued to stay largely attached (Bolzon et al., 2015, b, c). This resulted in the tubercled wing producing less lift near the wingtip, which resulted in a decreased induced drag coefficient and an increased profile drag coefficient compared to the smooth wing (Bolzon et al., 2015, b). This range of angles of attack is ideal for investigating the effects of induced and profile drag coefficients on the downstream, streamwise velocity distribution because of the change in the tubercles' effects on the induced and profile drag coefficients. Figures 13 and 19 depict the downstream, streamwise velocity distributions for the smooth wing at $9^{\circ}$ and $12^{\circ}$ angles of attack, respectively. The higher magnitude contours have increased in size and the velocity gradient has increased, and in addition Bolzon et al. [4] found that increasing the smooth wing's angle of attack from $9^{\circ}$ to $12^{\circ}$ resulted in an increase in both the induced and profile drag coefficients. Conversely, when the tubercled wing was pitched from $9^{\circ}$ to $12^{\circ}$ the induced drag coefficient reduced in the wingtip region, but the profile drag coefficient increased dramatically, because of flow separation [4]. From the downstream, streamwise velocity distributions of the tubercled wing at $9^{\circ}$ and $12^{\circ}$ presented in figures 14 and 20, respectively, it can be seen that increasing the angle of attack of the tubercled wing resulted in an increase in the lower magnitude contour sizes, but the velocity gradients of these lower velocity contours decrease dramatically, as labelled on figure 20. Therefore, it can be deduced that this expansion of the lower velocity contours coupled with a reduced velocity gradient was caused by flow separation. As this occurred near the wingtip, a reduction in the lift and hence induced drag coefficient resulted.

\subsection{The Effects of the Profile Drag Coefficient on the Downstream, Streamwise Velocity Distribution}

Decoupling the effects of the profile drag coefficient on the downstream, streamwise velocity is relatively simple compared to decoupling the induced drag coefficient 


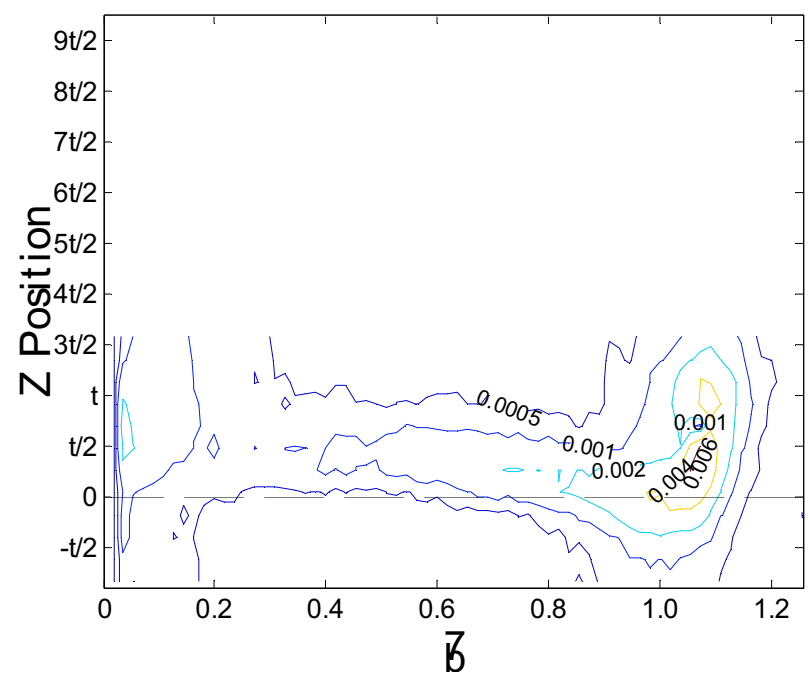

Figure 3. Induced drag coefficient distribution over the smooth wing at $3^{\circ}$.

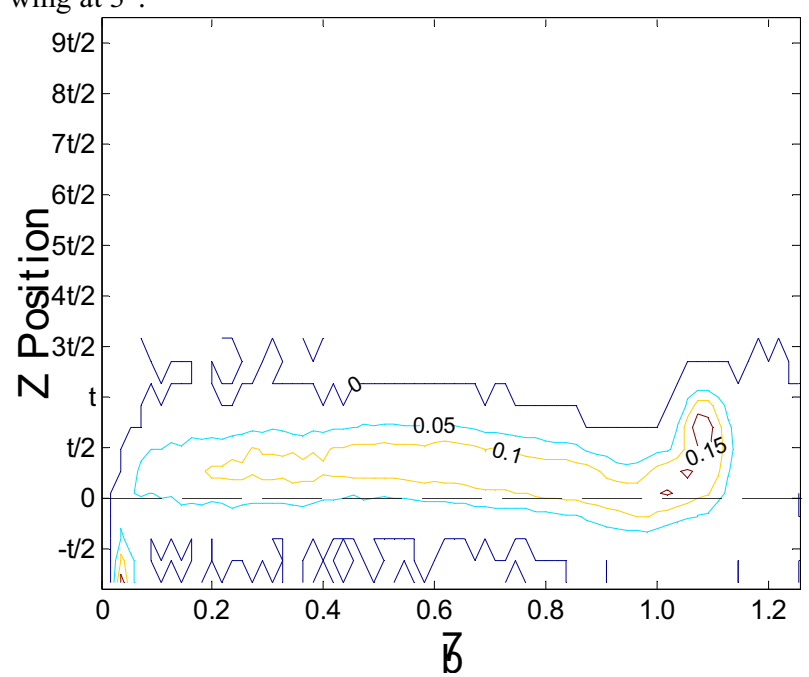

Figure 5. Profile drag coefficient distribution over the smooth wing at $3^{\circ}$.

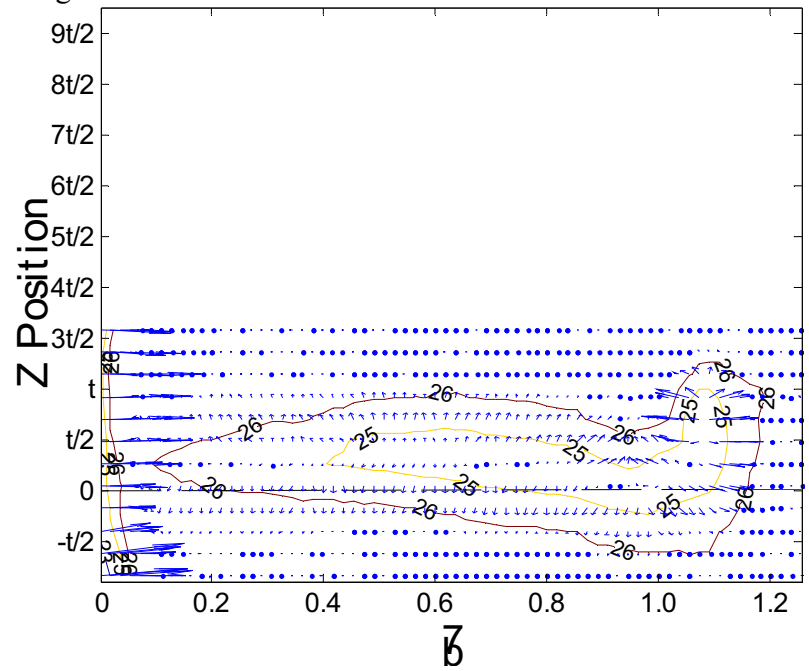

Figure 7. Downstream, streamwise velocity distribution over the smooth wing at $3^{\circ}$.

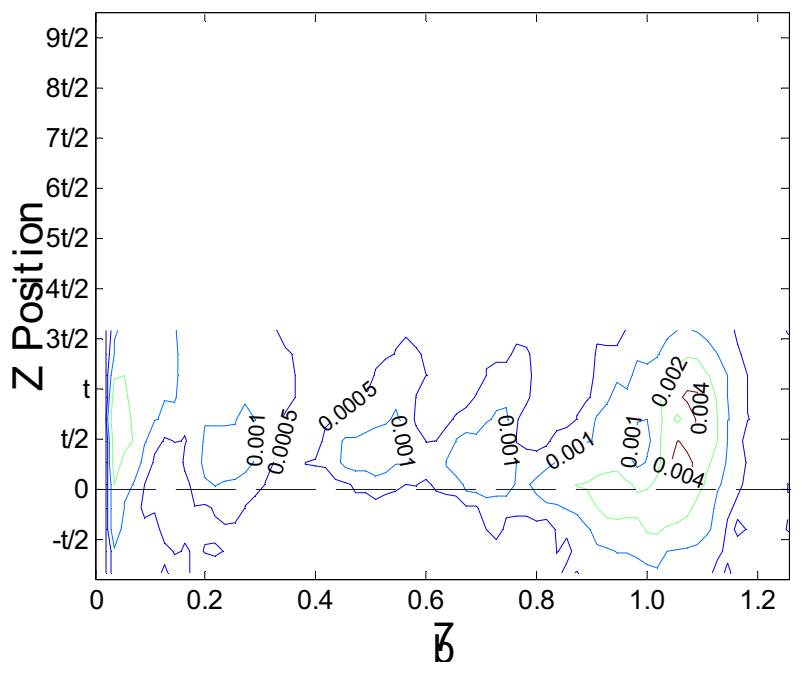

Figure 4. Induced drag coefficient distribution over the tubercled wing at $3^{\circ}$.

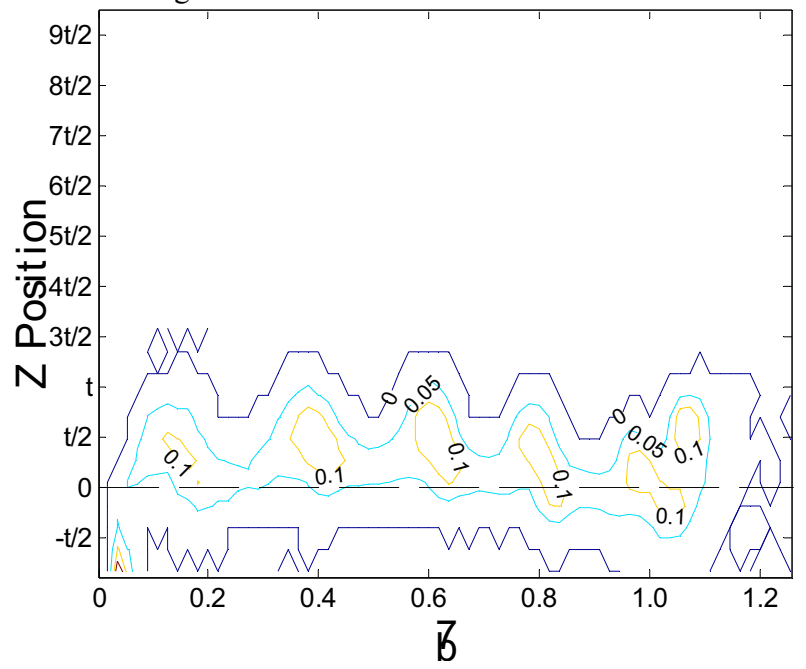

Figure 6. Profile drag coefficient distribution over the tubercled wing at $3^{\circ}$.

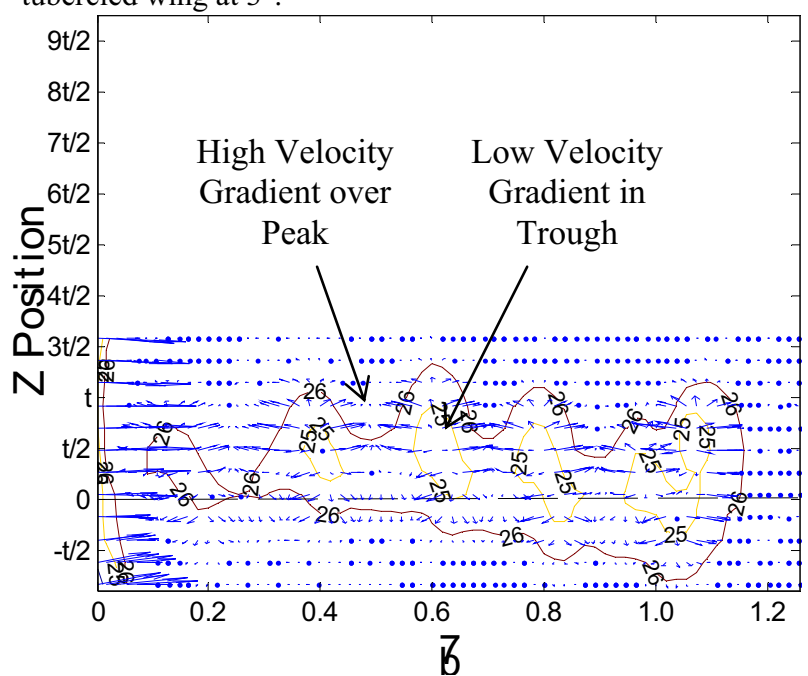

Figure 8. Downstream, streamwise velocity distribution over the tubercled wing at $3^{\circ}$. 


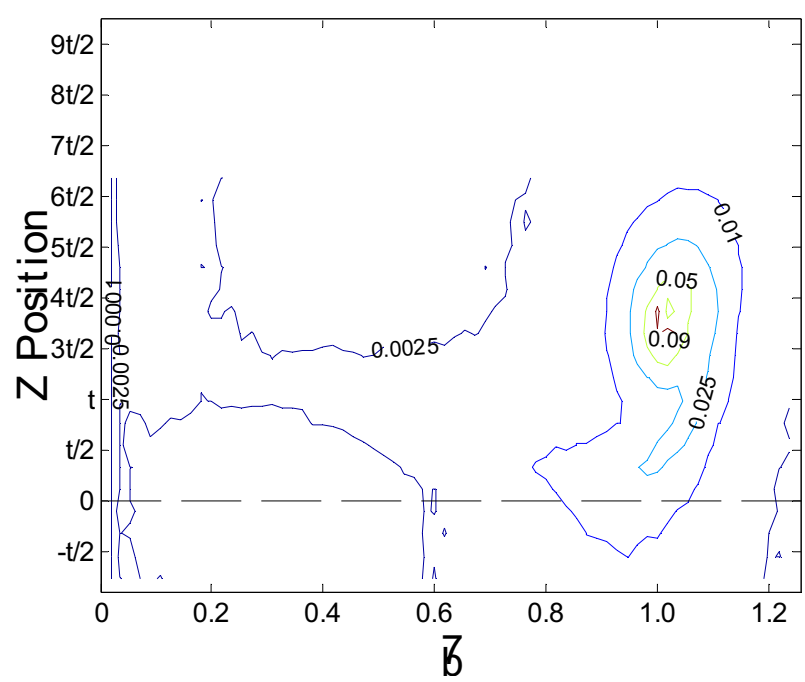

Figure 9. Induced drag coefficient distribution over the smooth wing at $9^{\circ}$.

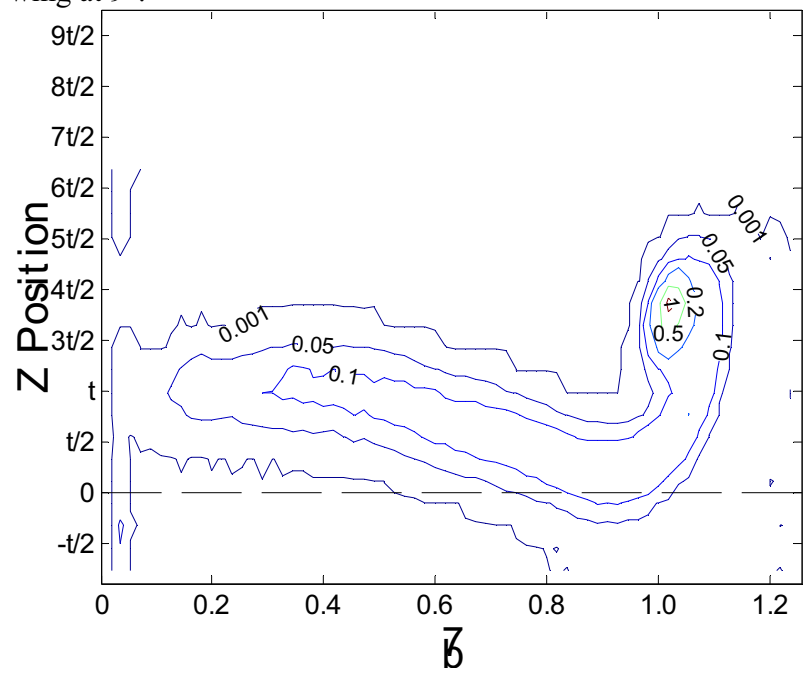

Figure 11. Profile drag coefficient distribution over the smooth wing at $9^{\circ}$.

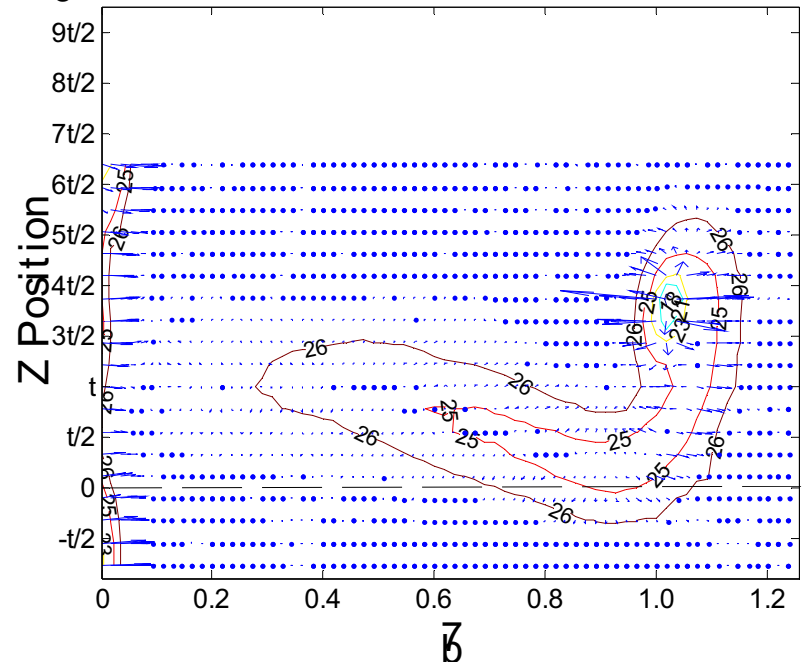

Figure 13. Downstream, streamwise velocity distribution over the smooth wing at $9^{\circ}$.

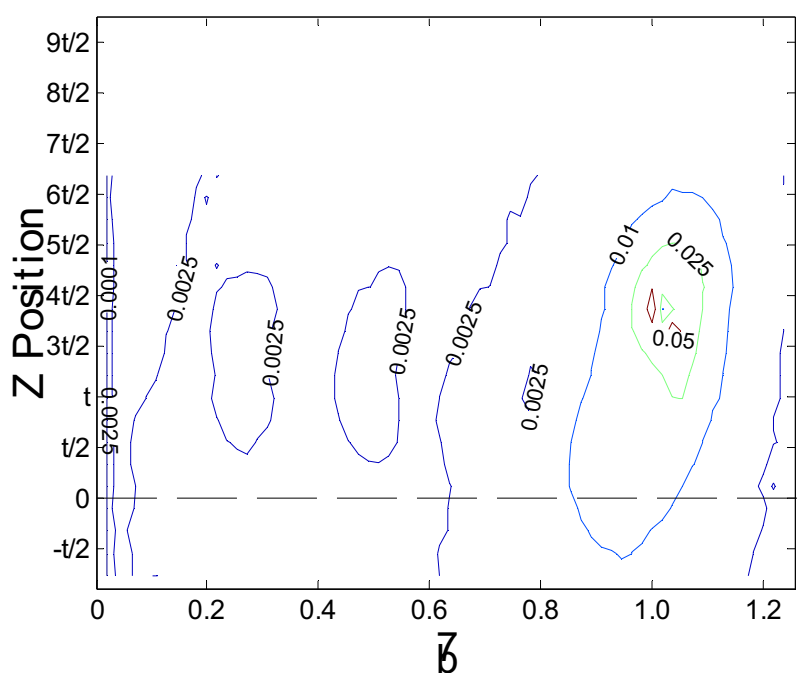

Figure 10. Induced drag coefficient distribution over the tubercled wing at $9^{\circ}$.

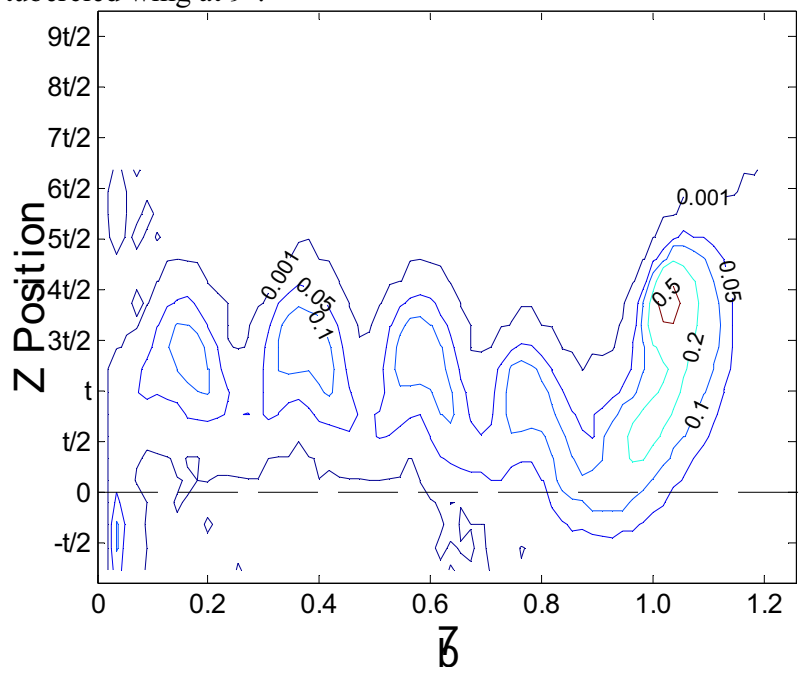

Figure 12. Profile drag coefficient distribution over the tubercled wing at $9^{\circ}$.

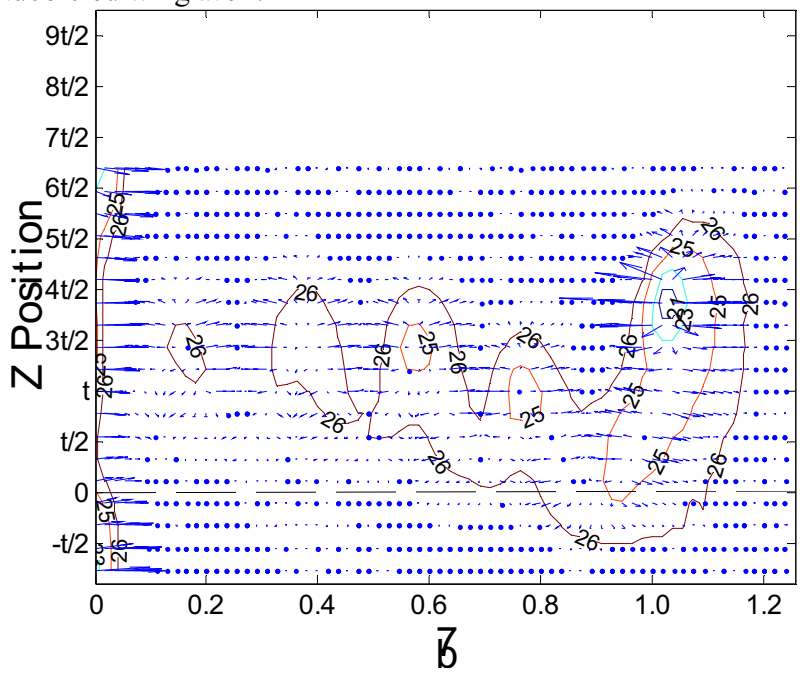

Figure 14. Downstream, streamwise velocity distribution over the tubercled wing at $9^{\circ}$. 


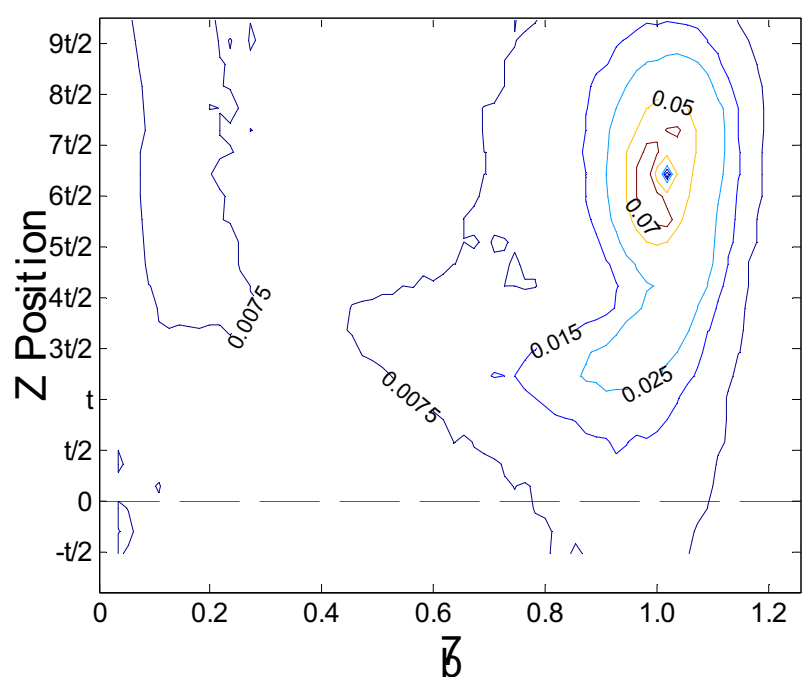

Figure 15. Induced drag coefficient distribution over the smooth wing at $12^{\circ}$

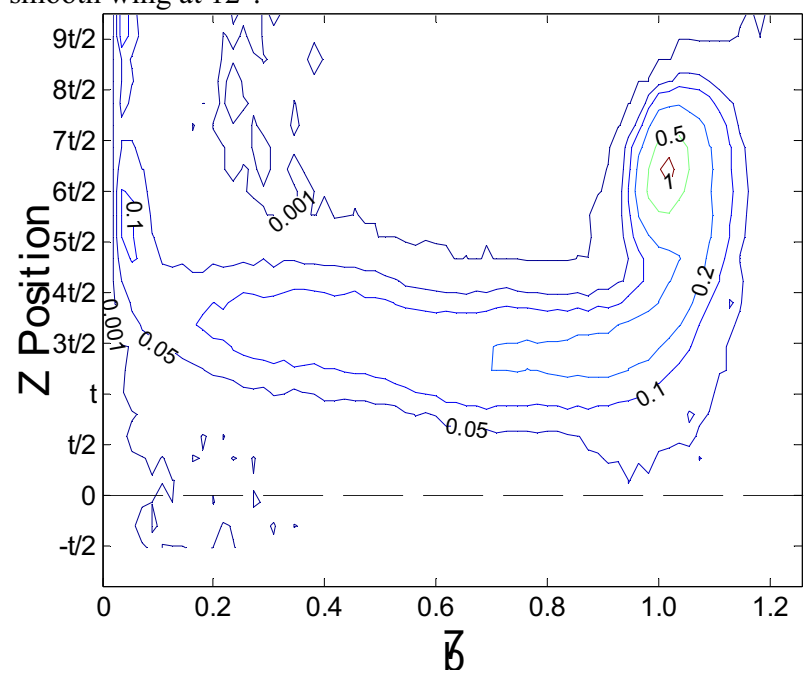

Figure 17. Profile drag coefficient distribution over the smooth wing at $12^{\circ}$.

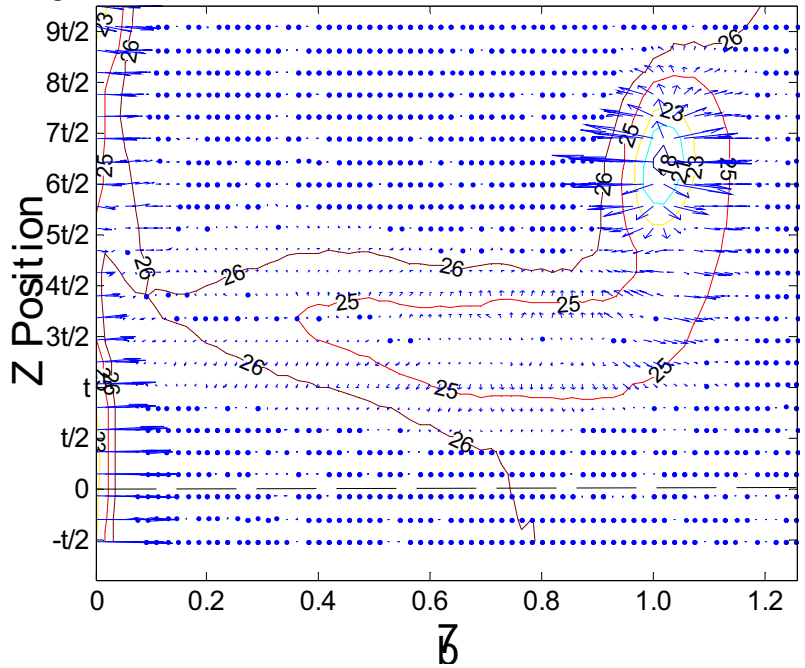

Figure 19. Downstream, streamwise velocity distribution over the smooth wing at $12^{\circ}$.

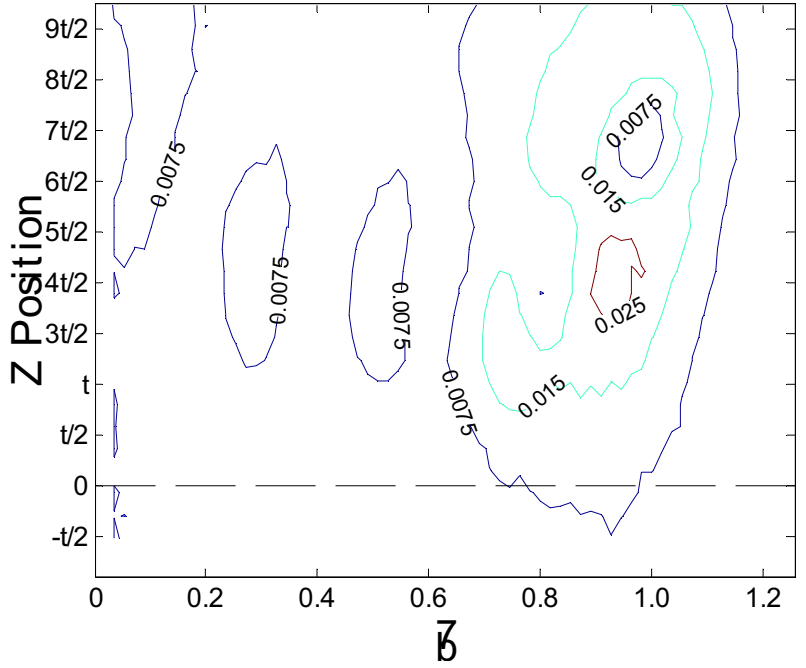

Figure 16. Induced drag coefficient distribution over the tubercled wing at $12^{\circ}$.

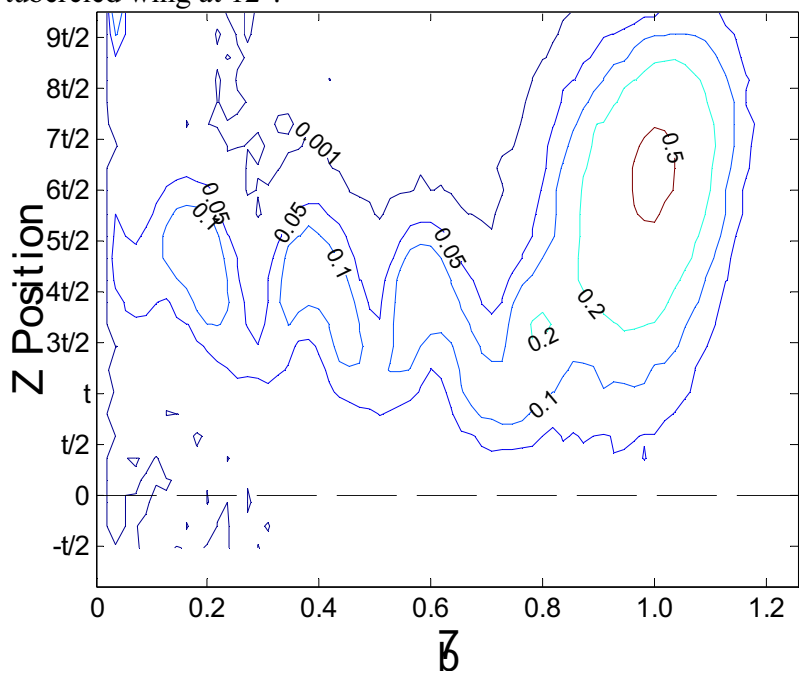

Figure 18. Profile drag coefficient distribution over the tubercled wing at $12^{\circ}$.

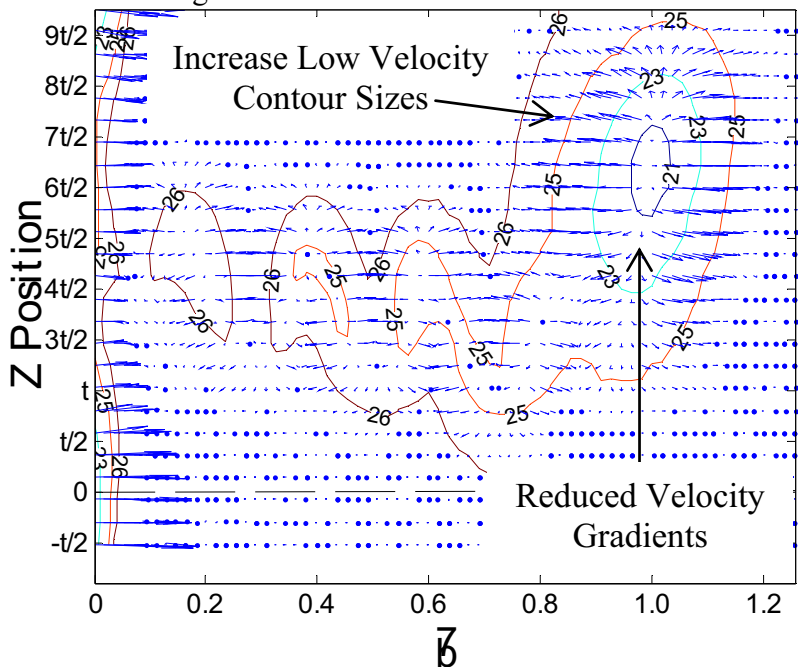

Figure 20. Downstream, streamwise velocity distribution over the tubercled wing at $12^{\circ}$. 
effects. It was already pointed out that the induced drag coefficient was largely localised to the wingtip region, therefore, the downstream, streamwise velocity over the span of a wing will largely reflect the profile drag coefficient. Evidence for this claim can be seen from the tubercled wing at any of the angles of attack presented. For example, at $3^{\circ}$ the tubercled wing modulated the profile drag coefficient into local maxima and minima, as shown in figure 6, and Bolzon et al. [4] found that these local maxima and minima correspond to the tubercle troughs and peaks, respectively. It was hypothesized that the local maxima were produced in the troughs as the flow separates more readily [4]. The downstream, streamwise velocity shown in figure 8 exhibits the same modulation. It should be noted that a reduction in the downstream, streamwise velocity will indicate an increase in the profile drag coefficient.

As has been explained previously, as the induced and profile drag coefficients are relatively large in the wingtip region, it is much more difficult to investigate the profile drag coefficient in this region purely from the downstream, streamwise velocity distribution. However, it was deduced that an increase in the downstream, streamwise velocity contour size in the wingtip region coupled with a reduction in the velocity gradient indicates flow separation, which subsequently resulted in an increase in the profile drag coefficient. While this relationship is useful, it is only applicable to angles of attack when the wing is stalling, hence a question arises as to whether the profile drag in the wingtip region can be deduced from the downstream, streamwise velocity at lower angles of attack.

For all of the angles of attack considered the profile drag coefficient in the wingtip region of either wing is significantly greater than the induced drag coefficient, therefore, the effect of the profile drag coefficient on the downstream, streamwise velocity will be substantially higher. As such, changes in the downstream, streamwise velocity in the wingtip region at lower angles of attack will typically indicate a change in the profile drag coefficient. This means that the effect of any change in the induced drag coefficient in the wingtip region on the downstream, streamwise velocity distribution at lower angles of attack is overshadowed by the profile drag coefficient effect.

\subsection{Investigating Stall from the Downstream, Streamwise Velocity Distribution}

Bolzon et al. [5] found that this tubercled wing begins to severely stall near the wingtip at an angle of attack of $12^{\circ}$, which results in an increase in profile drag coefficient and decrease in induced drag coefficient, as explained previously. The flow separation at the wingtip is easily identified from the downstream, streamwise velocity distribution in figure 20 where, as previously discussed, the expansion of the velocity deficit and reduction in the velocity gradient indicates an increased drag and lower lift production near the wingtip, which is arguably caused by flow separation.
For the smooth wing the flow separation follows a common pattern, where flow begins to separate at the trailing edge and progresses towards the leading edge with increasing angle of attack [5]. However, the flow separation pattern over the tubercled wing is far more interesting, as not only does the flow separate over the wingtip region, but in the troughs [5]. The known flow separation in the troughs is the cause of the localised increases in the profile drag coefficient that can be seen in figure 6,12 , and 18 . While it is easy to determine that these increases in the profile drag coefficient are caused by flow separation given the flow visualisation data obtained by Bolzon et al. [5], an aim of this study is to determine whether flow separation can be deduced solely from the downstream, streamwise velocity profile. In the wingtip region, a relationship between the size and gradient of the velocity deficit and the flow separation exists, and perhaps this same relationship can be extended to the flow separation in the troughs of the tubercled wing.

As highlighted in figure 8, the downstream, streamwise velocity gradient is much higher over the peaks than in the troughs. Furthermore, the lower velocity contours are much larger in the troughs than over the peaks, which can be likened to the wingtip expansion discussed previously. Therefore, similar conditions exist in the troughs as over the wingtip region when flow separation occurs, hence the criteria used to determine if the flow has separated in the wingtip region can also be used for the flow over the rest of the wing, namely increased lower velocity contour sizes and reduced velocity gradients in these contours. This suggests that the extent of flow separation over a wing can be investigated from the downstream, streamwise velocity distribution alone.

\section{Conclusion}

A wake survey has been conducted on two swept wings, one with a smooth leading edge and the other with a tubercled leading edge, at $3^{\circ}, 9^{\circ}$, and $12^{\circ}$. The induced and profile drag coefficient distributions of each wing were subsequently determined. The downstream, streamwise velocity profiles of each wing have also been found and patterns emerging from these distributions have been compared to the induced and profile drag coefficient distributions to ascertain potential relationships.

It was found that at angles of attack nearing stall, an expansion of the velocity contours in the wingtip region coupled with a reduction in the downstream, streamwise velocity gradient indicates a reduction in the induced drag coefficient and an increase in the profile drag coefficient. It was also found that if these two criteria are fulfilled then it can be deduced that the flow has separated regardless of the location over the wing. This is a particularly important result as flow separation typically results in an increase in the local profile drag coefficient.

At angles of attack where the flow is still mostly attached the induced and profile drag coefficients were not decoupled from the downstream velocity distribution 
alone. However, for all angles of attack considered the profile drag coefficient is considerably greater than the induced drag coefficient along the span of the wing, therefore, changes in the downstream, streamwise velocity distribution largely represent the profile drag coefficient, and as such changes in the profile drag coefficient can be determined. As the induced drag coefficient is overshadowed by the profile drag coefficient, determining the relative induced drag value from the downstream, streamwise velocity when the flow was still attached was not possible.

This study has found several interesting trends between the induced and profile drag coefficients and the downstream, streamwise velocity distribution, which suggests that valuable information about these components of drag, and whether the flow is attached, can be determined from a more simplistic approach. Further investigation is required to attempt to decouple the effects of the induced drag coefficient from the profile in the wingtip region on the downstream, streamwise velocity distribution when the flow is still attached.

\section{Acknowledgements}

Research undertaken for this report has been assisted with a grant from the Sir Ross and Sir Keith Smith Fund (Smith Fund) (www.smithfund.org.au). The support is acknowledged and greatly appreciated.

The Smith Fund by providing funding for this project does not verify the accuracy of any findings or any representations contained in it. Any reliance on the findings in any written report or information provided to you should be based solely on your own assessment and conclusions.

The Smith Fund does not accept any responsibility or liability from any person, company or entity that may have relied on any written report or representations contained in this report if that person, company or entity suffers any loss (financial or otherwise) as a result.

\section{References}

1. G.W. Brune, J. Aircraft Vol. 31, 7 (1994)

2. K.L. Hansen, Ph.D. Dissertation, The University of Adelaide (2012)

3. M.D. Bolzon, R.M. Kelso, M. Arjomandi, AIAA Journal (under review)

4. M.D. Bolzon, R.M. Kelso, M. Arjomandi, AIAA Journal (under review)

5. M.D. Bolzon, R.M. Kelso, M. Arjomandi, Phys. Fluids (under review) 